\title{
INVOLUNTARY CHILDLESSNESS
}

\author{
P. A. VAN KEEP AND H. SCHMIDT-ELMENDORFF* \\ International Health Foundation, Geneva, Switzerland, and \\ * Department of Obstetrics and Gynaecology, University of Dusseldorf, West Germany
}

(Received 13th February 1974)

\begin{abstract}
Summary. The problem of involuntary childlessness and its effect on marital happiness has been studied in an investigation involving interviews with 75 childless couples and a matched control of 75 couples with children. Marital happiness in various phases of the couple's relationship is plotted; in childless women this is seen to fall to its lowest ebb during the phase immediately before the problem is brought to the attention of the doctor, whilst in men it occurs whilst waiting for the medical diagnosis to be made. It seems that whilst childless marriages in themselves are not necessarily less happy than those with children (though all the childless couples interviewed had sought to change their situation by seeking medical help) such marriages are based on a different equilibrium from that of couples. with children. In childless marriages there is often closer communication between the partners and a greater degree of communis opinio. People with children are sometimes over-careful in their approach to those without children. Attitudes and behaviour with regard to fidelity are seen to differ; the childless couples interviewed were less permissive in this respect than those with children. Alternatives in the form of artificial insemination, adoption, careers and pets are briefly considered.
\end{abstract}

\section{Introduction}

In recent times the social pressure on married couples to have children has lessened considerably. Nevertheless the vast majority of couples marrying today do intend to have children. It seems likely that when a marriage remains childless against the wishes of the couple, marital satisfaction will be endangered; but it is also possible that the childlessness itself will strengthen the bond between the partners and increase solidarity. Involuntary childlessness, therefore, may lead to a marriage which is less happy than it might otherwise have been, or to a marriage based on an equilibrium which is different from that of marriages with children.

Figures from the Mikrozensus of the Statistisches Bundesamt show that in Germany in $197010 \%$ of marriages contracted 10-14 years earlier were still without 
children. Applying an earlier finding to this figure, one-fifth were probably voluntarily childless (van Keep, 1971). One in twelve of all couples, therefore, is probably involuntarily without children. Bierkens (1973) found in Holland that a surprisingly high proportion of childless couples-50 of the 155 interviewed-had never asked for medical help, though only eight said that they were without children by choice. The others gave a variety of reasons for not having consulted a doctor, most of which do not sound very plausible, especially when one considers that nowadays it is relatively well known that many cases of childlessness can be helped with medical treatment.

With the present study it was intended to take a look at the problems faced by couples when they do not have the children they want, and to see how the attitudes of these couples towards the problem and towards marriage and children in general, compare with those of couples who have children. All the childless couples interviewed were receiving treatment for their childlessness, and none was completely without hope of having a child one day. In view of this the couples interviewed cannot be regarded as being representative of childless couples in general, nor even of involuntarily childless couples. However, since $60 \%$ of those interviewed had been receiving treatment for more than 3 years, and so had probably been trying unsuccessfully to have a child for 4 years or more, it is not unreasonable to say that most of the couples interviewed had got used to married life without children.

\section{Study procedure}

The study was based on interviews with 300 people, 150 married couples. Half were childless and half had succeeded in having at least one child. The childless couples were grouped according to the length of time which had passed since they first sought medical advice in connection with their childlessness, and they were matched with couples whose first child was born at that time (Table 1). Taking into account the income of the husbands and the degree of education of both partners, all 150 couples were classified as upper middle class. The women were all under 41 years of

Table 1. Matched groupings of the respondents

\begin{tabular}{|c|c|c|c|}
\hline Group & $\begin{array}{l}\text { Length of time since help was first } \\
\text { sought/length of time since the birth } \\
\text { of the first child }\end{array}$ & $\begin{array}{l}\text { No. of } \\
\text { childless } \\
\text { couples }\end{array}$ & $\begin{array}{l}\text { No. of } \\
\text { couples with } \\
\text { children }\end{array}$ \\
\hline $\begin{array}{l}\text { A } \\
\text { B } \\
\text { C } \\
\text { D } \\
\text { E }\end{array}$ & $\begin{array}{l}1 \frac{1}{2} \text { years or less } \\
1 \frac{3}{4}-3 \text { years } \\
3 \frac{1}{4}-6 \text { years } \\
6 \frac{1}{4}-9 \text { years } \\
9 \frac{1}{4}-15 \text { years }\end{array}$ & $\begin{array}{l}15 \\
15 \\
15 \\
15 \\
15\end{array}$ & $\begin{array}{l}15 \\
15 \\
15 \\
15 \\
15\end{array}$ \\
\hline & Total & 75 & 75 \\
\hline
\end{tabular}


age. Fifty-nine ( $79 \%$ ) of the childless women had paid jobs, 23 part-time ( 30 hours or less per week) and 36 full-time. Understandably, rather fewer of the women with children had jobs: $23(31 \%), 14$ part-time and 9 full-time. Women with children who had become pregnant before their marriage were excluded from the control group.

The study was conducted between October 1971 and March 1972. The interviews, which were conducted with the aid of a questionnaire, were carried out by professional interviewers with training in psychology. They were held either in the clinic or in the homes of the respondents. The men were interviewed by men and the women by women, allowing no time for discussions between the partners.

In several instances the respondents were asked to give their opinions about certain statements, e.g. 'I often have the feeling that in my presence people try to avoid the subject of children' and 'Social contact with couples who can't have children is often somewhat difficult'. The respondents were asked to indicate their feelings by replying with a number, from 1 , indicating that they completely disagreed with the statement, through to 6 , indicating that they completely agreed with it. The opinion of the sample as a whole, or that of specific subgroups, has been assessed by totalling the replies of the individuals concerned and dividing this total by the number of people in the group. The resultant figure is referred to in this paper as 'the average rating'. Obviously, the higher the average rating, the greater the tendency of the group as a whole to agree with the sentiments expressed in the statement. When the average rating is less than 3.5 it may be said that the group as a whole tends more to disagree with it.

\section{Findings}

\section{Subjective assessment of marital happiness}

An interesting picture emerged when the respondents were asked to assess their happiness during various phases of their relationship. The six phases chosen differed slightly for the two groups, and the duration of each phase obviously varied from one couple to another. They were:

For the childless couples

Phase I

Phase II

Phase III
From the engagement until the marriage

From the marriage until the decision to become pregnant

From the decision to become pregnant until the time they began to realize that this did not happen
For the couples with children

From the engagement until the marriage

From the marriage until the decision to become pregnant

From the decision to become pregnant until pregnancy 


$\begin{array}{lll}\text { Phase IV } & \begin{array}{l}\text { From the time they began } \\ \text { to think that something } \\ \text { might be wrong until the } \\ \text { first visit to a doctor }\end{array} & \text { During the first pregnancy } \\ \text { Phase V } & \begin{array}{l}\text { From the first visit to a } \\ \text { doctor until a diagnosis } \\ \text { was made }\end{array} & \begin{array}{l}\text { From the birth of the first } \\ \text { child until that of the } \\ \text { second (or until now) }\end{array} \\ \text { Phase VI } & \begin{array}{l}\text { From hearing the diagnosis } \\ \text { until now }\end{array} & \begin{array}{l}\text { From the birth of the } \\ \text { second child until that of } \\ \text { the third (or until now) }\end{array}\end{array}$

The considerable difference between the two groups is clearly illustrated in Text-fig. 1. The tremendous drop in the graph of the childless women occurs when they are worried about the lack of a wanted pregnancy. The graph begins to rise once the problem is brought to the attention of a doctor. The graph for the childless men is similar, though it does not drop to as low a level as that of the childless women; it also tends to rise a little later, once the diagnosis is made.

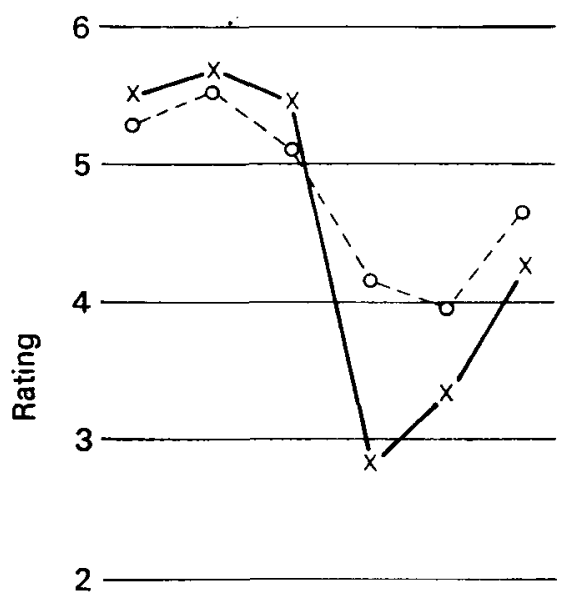

(a)
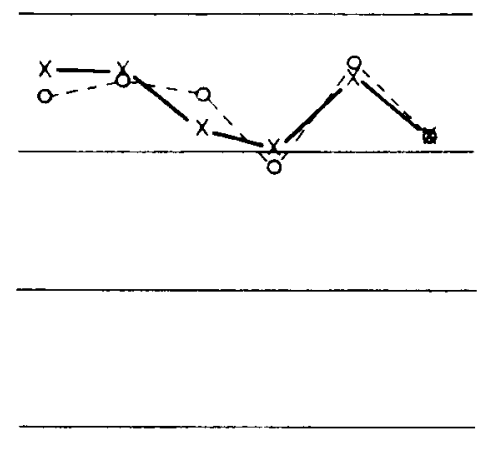

(b)

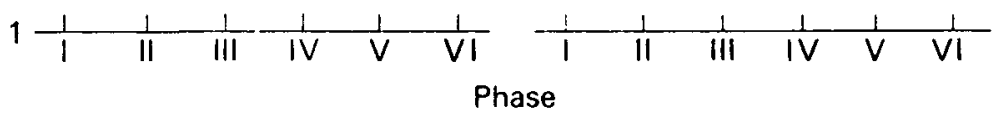

Text-fig. 1. Respondents' subjective assessment of their happiness in various phases since the engagement: (a) childless respondents, (b) respondents with children. Men, $O$; women, $\times$. (See text for explanation of phases and ratings.) 
The graphs of the respondents with children fall to their lowest point at a comparable time, which for these couples is during the first pregnancy. The degree of the drop, however, is hardly comparable to that of the respondents without children.

\section{Communication between marriage partners}

The degree of communication between the partners was investigated by asking the respondents to say what they thought their partner's views were on a number of points, and then comparing the answers with the partner's actual opinions. Four points were chosen: preferred company for a holiday, the number of social visits made by the couple, the amount of personal appreciation received from the marriage partner, and the feelings about the closeness of the partners' relationship.

It emerged that the childless couples were completely right in $57 \%$ of the instances, partially right in $32 \%$, and completely wrong in $11 \%$. The couples with children were completely right in $42 \%$ of the instances, partially right in $39 \%$, and completely wrong in $18 \%$. This suggests that communication is better between couples without children than between those with children. It seems likely, however, that there is a particularly high degree of rapport between childless partners who present themselves for treatment for their infertility; their communication must be good for them to take action in this way. It is possible that it would not be found to be so good in a randomly selected group of childless couples.

Text-figure 2 gives a breakdown of the data according to the amount of time that had passed since the childless respondents first sought help for their childlessness, or since those with children first became parents, as described under Study Procedure. Although the groups were rather small, fifteen couples in each, an interesting picture emerged. Communication was best in subgroup B of the childless couples, but for the couples with children it was at its worst at this time. This might be explained by the fact that couples in this subgroup had young children at home, a situation which may interfere with communication between partners. This may also explain why communication in subsequent subgroups is better, as by then the children are growing older. The reason for communication between childless partners being at its worst in subgroup $\mathrm{C}$-couples who had sought help for their infertility between $3 \frac{1}{4}$ and 6 years earlier-is not clear.

\section{Communis opinio}

A second factor considered was the degree of communis opinio between the partners, the extent to which the opinions of the two partners were similar. Eleven points were included in this section: preferred company for a holiday; common hobbies and interests; the amount of free time spent together; opinions about the amount of time spent together; opinions about the number of social visits made together; preferred company; opinions about being in the company of children; opinions about the happiness of one's own marriage compared with others; personal 

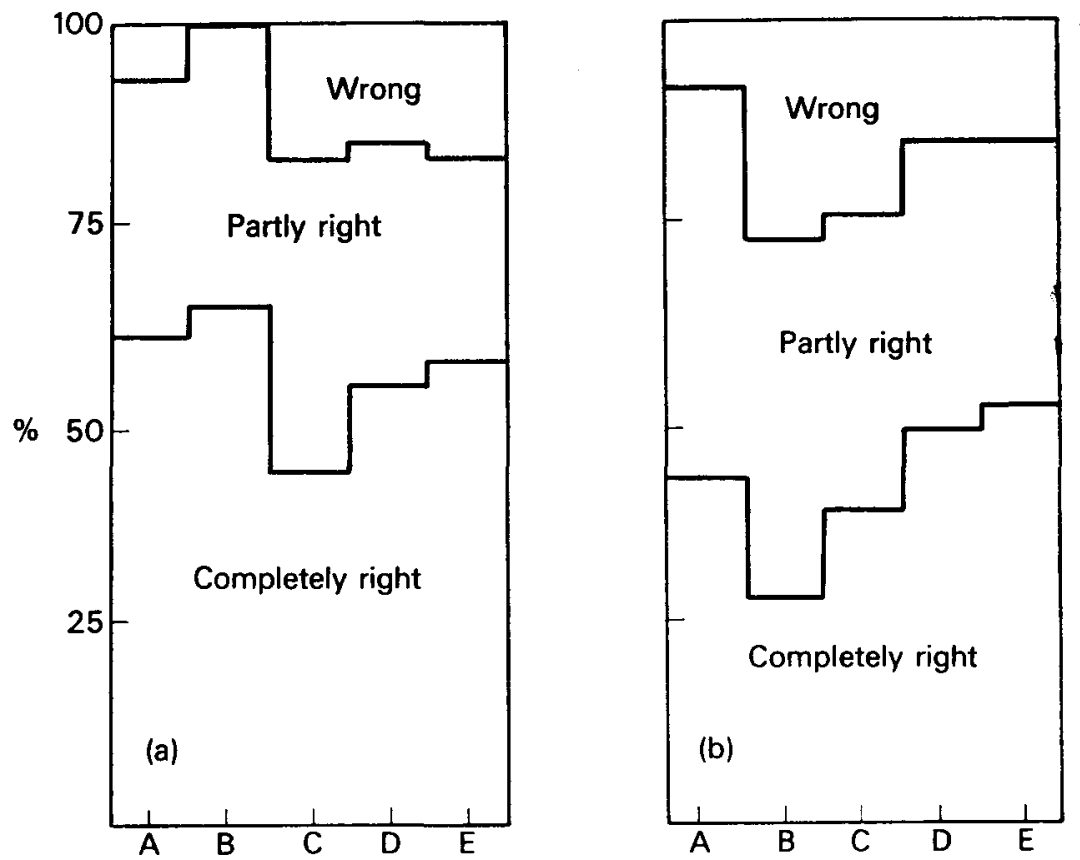

Text-fig. 2. Average knowledge about partners' opinions, as a measure of communication, according to subgroups: (a) couples without children, (b) couples with children.

appreciation received from partner; feelings about the 'closeness' of the marital relationship; opinion about the involvement of relatives in the couple's affairs.

When the couple's opinions were compared it was again found that a higher degree of agreement existed between the couples without children than in those with children (Table 2). Further analysis of the subgroups showed that there is definitely less similarity of opinion between partners when there are young children in the family, although the differences were less outspoken asfound for 'communication.'

\section{Attitudes towards children}

Most of the people interviewed had a favourable attitude towards children. All the childless respondents wanted to have at least one child, and only five $(3 \%)$ of

Table 2. Incidence of similarity of opinion between marriage partners

\begin{tabular}{l|c|c}
\hline Agreement & $\begin{array}{c}\text { Childless } \\
\text { couples } \\
(\%)\end{array}$ & $\begin{array}{c}\text { Couples } \\
\text { with } \\
\text { children } \\
(\%)\end{array}$ \\
\hline Complete & 71 & 58 \\
Partial & 25 & 34 \\
None & 4 & 8 \\
\hline
\end{tabular}


those with children said that they considered a childless family ideal. Even other people's children appear to be well appreciated: $90 \%$ of the childless respondents and $65 \%$ of those who already had children of their own said that they liked being in their company.

The respondents' attitudes towards the rôle of children in a marriage-as someone to take care of, to play with, and to give life more purpose and varietyrevealed few significant differences of opinion between the two groups, but there was a tendency for more importance to be attached to this aspect by the childless respondents than by those with children. Similarly, the childless respondents were more inclined to minimize the inconvenience of parenthood, but between the two groups the differences were not significant.

The importance of continuing the lineage did not emerge as an important point in the opinion of either group, though it would appear to be slightly more important to the childless people than to those with children. The average degree of agreement (on the scale 1-6) with the statement: 'When one has children one is less afraid of dying as one knows that the family will continue' was $2 \cdot 1$ for the childless respondents and 1.5 for those with children. When the childless respondents were asked their opinions about 'It is important for men that the lineage is continued' the figures on the same scale were 2.2 for the men and 2.4 for the women. (The respondents with children were not asked this question.)

When they were asked what they regarded as the ideal number of children the average of the childless respondents was $2 \cdot 21$, and that of the respondents with children was $2 \cdot 24$. The most frequently mentioned individual number was 2 , which was regarded as ideal by $116(77 \%)$ of the childless respondents, and by $90(60 \%)$ of those with children. The only other number of any importance was 3 , which was regarded as ideal by $26(17 \%)$ of the childless respondents, and by $31(51 \%)$ of those with children.

\section{Attitudes towards sterility}

Most of the childless people interviewed said that they were 'greatly disappointed' when they learned that their marriage would probably remain childless; the figures relating to the statement on this point were $4 \cdot 1$ for the men and $5 \cdot 7$ for the women, giving an average of 4.9 for the whole group.

The figures for 'I married mainly to have children' were 2.5 for the childless men and 1.5 for the women, but neither the childless respondents nor those with children considered sterility to be a reason for divorce. The figures on this point were 1.2 for the childless group and 1.4 for those with children.

In general it was felt that childlessness is more difficult a problem for women than for men. The figures in connection with 'How difficult a problem is childlessness for you now?' were 3.4 for the men and 4.6 for the women, with an average of 4.0 for the whole group. Most of the respondents with children felt that they would have 
been unhappy if they had not been able to have children: 4.1 for the men and 4.4 for the women.

Table 3, which gives the replies to the question 'For whom is the disappointment (over the inability to have children) greater?', shows an interesting difference between the attitude of the childless men and that of the men with children, the latter group being far more inclined than the former to feel that men as well as women will find the lack of children a disappointment.

Table 3. Replies to the question: 'For whom is the disappointment (over the inability to have children) greater?'

\begin{tabular}{l|cc|cc}
\hline & \multicolumn{2}{|c|}{ Childless couples } & \multicolumn{2}{c}{ Couples with children } \\
\cline { 2 - 5 } & $\begin{array}{c}\text { Men } \\
(\%)\end{array}$ & $\begin{array}{c}\text { Women } \\
(\%)\end{array}$ & $\begin{array}{l}\text { Men } \\
(\%)\end{array}$ & $\begin{array}{c}\text { Women } \\
(\%)\end{array}$ \\
\hline Greater for the husband & 1 & 1 & 4 & 5 \\
Greater for the wife & 72 & 45 & 39 & 38 \\
Equal for both & 24 & 50 & 54 & 56 \\
Cannot say & 3 & 4 & 3 & 1 \\
\hline
\end{tabular}

Most of the childless respondents, particularly the men, said that their acquaintances did not know that their marriages were involuntarily childless; the figures were 4.8 for the men, and 4.1 for the women, giving an average of 4.6 for the whole group. The men were slightly less inclined than the women to welcome the opportunity to talk about their childlessness; the figures relating to the statement 'I like it when I can speak to someone about the childlessness of our marriage' were 2.3 for the men, 2.5 for the women, with an average of $2 \cdot 3$ for the group.

This difference was also seen when the respondents were asked which nonmedical people they had discussed their problem with. The women mentioned rather more people than the men did (Table 4).

It would seem that many people avoid mentioning the subject of children when in the presence of people who cannot have children of their own. When the respondents who already had children were asked how they felt about 'Social contact with

Table 4. Non-medical people with whom the childless respondents had discussed their problem

\begin{tabular}{l|c|c|c}
\hline \multicolumn{1}{c|}{ Problem discussed with: } & No. of men & No. of women & Total \\
\hline Friends & 7 & 27 & 34 \\
Colleagues at work & 7 & 21 & 28 \\
Relations in own family & 2 & 11 & 13 \\
Boss at work & 3 & 7 & 10 \\
Relations in partner's family & 1 & 2 & 3 \\
Others & 1 & 10 & 11 \\
\hline
\end{tabular}


couples who can't have children is often somewhat difficult' the average figure was 3.5 , and these respondents also agreed that they '... don't like to speak about my children in the presence of couples who can't have children' (4-2) and 'When I meet a couple who can't have children I try to lead the conversation in such a way that the subject of children is not raised' $(4 \cdot 1)$.

It seems, however, that childless couples are not often aware of this careful approach. The degree of agreement with ' $I$ have the feeling that people deal with me in a somewhat different way from couples with children' was only 1.6 for both men and women. The figures in connection with ' $I$ often have the feeling that in my presence people try to avoid the subject of children' were 1.5 for the men, and 1.3 for the women. They were slightly more inclined, however, to agree that they '... always feel somewhat excluded when people talk about their children': $2 \cdot 1$ for the men, 3.2 for the women, and 2.5 for the group as a whole.

\section{Fidelity}

The childless respondents had a rather different attitude from those with children about the importance of fidelity in marriage. They were more inclined to disapprove of extra-marital affairs and were more ready to consider divorce if their partner was unfaithful.

Figures relating to the statement 'An occasional affair is sometimes good for a marriage' were 2.9 for the childless respondents, and 3.5 for those with children. There were no differences between the opinion of the men and that of the women within each group.

Figures for 'A married woman should never have an affair' were $5 \cdot 1$ for the childless respondents, but only $4 \cdot 1$ for those with children. Similarly, the figures for ' $A$ married man should never have an affair' were 4.9 for the childless respondents and 3.7 for those with children. There was some evidence of a double-standard in the minds of both groups of men interviewed, but not in the minds of the women (Table 5).

Table 5. Average ratings of the men and women in each sub-group on statements relating to extra-marital affairs

\begin{tabular}{l|c|c}
\hline \multicolumn{1}{c|}{ Respondents } & $\begin{array}{c}\text { 'A married woman } \\
\text { should never } \\
\text { have an affair' }\end{array}$ & $\begin{array}{c}\text { 'A married man } \\
\text { should never } \\
\text { have an affair' }\end{array}$ \\
\hline Childless men & $5 \cdot 1$ & $4 \cdot 7$ \\
Men with children & $4 \cdot 4$ & $3 \cdot 6$ \\
Childless women & $5 \cdot 1$ & $5 \cdot 1$ \\
Women with children & $3 \cdot 8$ & $3 \cdot 8$ \\
\hline
\end{tabular}

NB: The higher the figure the greater the degree of agreement with the statement. 
The childless respondents were rather more inclined than those with children to agree with the statement 'If my partner was to have affairs I would seriously consider divorce'. The figures were 4.6 for the childless respondents, but only 3.9 for those with children; there were no differences between the opinion of the men and that of the women within each group. This difference in attitude between the two groups reflects the differences in their attitudes towards infidelity; it is also true, of course, that once a couple has children there is an added reason not to divorce.

Differences were also seen when the respondents were asked about their own faithfulness. Whilst $83 \%$ of the childless respondents said that they had always been faithful, this was so for only $61 \%$ of those with children. The childless respondents also had higher expectations of their marriage partners in this respect: $78 \%$ said that they thought their partners had always been faithful, compared to only $55 \%$ of those with children.

\section{Alternatives to childlessness}

Four topics were discussed under this heading: artificial insemination, adoption, careers and pets.

Artificial insemination. The statement "A woman whose husband is sterile should have artificial insemination' was not really accepted by most of the people interviewed, though it was slightly more acceptable to the childless respondents (3.0) than to those with children (2.6). Lack of enthusiasm on this point even by the childless respondents may be explained by the fact that most of the childless couples interviewed regarded themselves as cases of female sterility for which artificial insemination would be of no use.

Adoption. Only four of the 75 childless couples had already adopted a child. These were all couples who had been receiving treatment for more than 9 years. Seven of these eight people said that they would like to adopt more children. Only $57 \%$ of the other childless respondents said that they had seriously thought of adopting, but $79 \%$ of those who had not so far adopted said that they could imagine that in certain circumstances they might. The attitudes of the childless respondents and of those with children were similar; a figure of 4.5 was returned for both groups in connection with 'A couple who can't have children should adopt.'

Careers. There was some support, more from the respondents with children than from those without, for the thought that childless people, particularly the women, may find solace for their childlessness in a career. The relevant statements and figures were: 'Childless couples should try to realize something special in their careers', with figures of 2.9 for the childless respondents and 3.4 for those with children, and 'A woman who can't have children should try to make a career', where the figures were 3.7 for the childless couples and $4 \cdot 1$ for those with children. There was no indication that careers in the social field, or involving contact with children, were preferred either by the childless women or by the men. 
Pets. The oft-mentioned stereotype of a childless couple lavishing affection on a domestic pet was borne out to some extent by the findings of this study; certainly the childless respondents were somewhat more enthusiastic and tolerant than those with children about having a domestic animal in the house. The relevant statements and figures were: 'When one has an animal in the house life is more varied', with figures of 4.0 for the childless respondents and 3.1 for those with children, and 'Animals bring a lot of irritation and unrest', where the figures were 3.1 for the childless respondents and 3.6 for those with children. Neither group, however, was prepared to doubt that 'Even the nicest animal can't substitute for a human being'the figures were 5.7 for the childless respondents, and 5.8 for those with children.

\section{Discussion}

It is generally supposed that couples who are involuntarily childless are less happy than those with children. Whilst to some extent this may be true of the childless couples interviewed, since they had all actively sought to change their situation, nothing in this study indicated that the marriages of these couples in themselves are less happy than those of couples who have succeeded in having children. What is clear is that the marriages of childless couples have a different basis from those of other couples. Whereas the marriages of couples with children are what might be labelled 'family-orientated', those of couples without children are 'partnerorientated'. Circumstances both force and allow them to be so. There is often a better degree of communication between the childless partners, and more communis opinio, both factors which may be said to be indicative of marital satisfaction. It may be, however, that the differences between the childless couples and those with children in this respect result, at least to some extent, from a specific characteristic of childless couples who, like those interviewed, actively seek help for their childlessness, since in order to take action in this way communication between the partners is probably rather good.

There was no evidence of any differences between the two groups as far as attitudes towards children were concerned: both groups were clearly favourably inclined - as was expected.

One of the biggest differences to emerge between the two groups was in connection with the attitudes towards infidelity. The fact that the childless respondents were considerably less permissive in this respect than those with children may well be related to the fact that in a childless marriage there is a greater danger of infidelity leading to the break up of the marriage.

Undoubtedly one of the more important points to emerge in this study was the extent to which personal happiness decreases when one does not have the child one hopes for, but increases once medical advice is sought for the problem. It is the authors' feeling that all too often this period is made unnecessarily long by the couples' unwillingness to admit even to themselves that something may be wrong. 
There is every reason to suggest that couples should seek medical help when no pregnancy has occurred after 6 months of unprotected intercourse.

\section{Acknowledgment}

The authors are grateful to Dr H. O. Mayer of Stuttgart for his assistance in connection with this study.

\section{References}

BIERKENs, P.B. (1973) Psychologische aspecten van het kinderloze echtpaar. Ned. T. Geneesk. 117, 770.

KEEP, P.A. VAN (1971) Ideal family size in five European countries. J. biosoc. Sci. 3, 259. 